\title{
Images of Women in Namitha Gokhale's Works
}

\author{
P. V. Vinitha ${ }^{1}$, Dr. K. Usha Rani ${ }^{2}$ \\ ${ }^{1}$ Research Scholar, ${ }^{2}$ Assistant Professor \\ Department of English, K. L. Deemed to be University, \\ Vaddeswaram, Guntur, Andhra Pradesh, India
}

\begin{abstract}
Namita Gokhale, an Indian woman novelist, one who builds up her works with a different vision. She involves a unique positioning in the Indian women works. She depicts her female characters act with more mettle and opportunity as opposed to requesting rights in the general public or featuring the issues of women. Her portrayal gives new bearings to the feministic compositions. Namita characters strongly confront any circumstance in their life, neither longed for the recommendations of the male. They are autonomous to take choices throughout their life and they have the ability to change the social standards with their individual contemplations. The present paper focuses on the advancement of women characters in the Namita Gokhale's works, speaks to how these characters battle to lead their lives and how they change the standards of conventional society to lead their lives and how they make a picture of new women with their considerations.
\end{abstract}

Key words: Modern women, fearlessness, opportunity, social standards

\section{INTRODUCTION}

The photo of the woman is remarkable as a given, unprotestingly, surrendered, a liberal creature of the man-driven social set up the world over. She has been socially altered to be an immaculate companion, a mother and a wonderful homemaker with diverse roles in the family. The women have been portrayed as the epitome of faultlessness and extraordinary power and viewed as bona fide animals from one perspective and on the other, saw as being essentially weak creatures continually requiring the affirmation of man as their ruler and expert. Extending number of women are ending up substantiating themselves. The sexual introduction value is the fundamental instrument to roll out a cordial improvement for men and women both. Gigantic quantities of the Indian women creators revolve around women's issues; they have a women's perspective on the world. Namita Gokhale is a versatile character who writes in English and is one of India's most applauded the writers who have touched the beat of the overall population by commending uncontrollably strong, burning, and definitive, individualistic women who are social images, with the extraordinary sentiment dependability to the clan and gathering. Her works voice a contradiction, an undertaking to grow "new selves in new structures". On getting some data about the condition of women in India, Namita Gokhale answered,

"... Things haven't changed. Prior women used to attempt to be pleasant customary spouse material... Girls from great families were made to convey one major towel in their packs so they would dependably twist as it shouldn't regard stand straight. They were advised to have a somewhat bowed stance... ..these days you assume to look thin and glitzy constantly. What an exercise in futility to do everything the time. I am not hostile to that but rather the entire thing to fitting into a shape, not being your identity. That is the thing that I discover, I think, some place every one of my books attempt to push women subliminally to simply be regular, unconstrained and themselves." (1)

Namita Gokhale has depicted some colossal women characters. Aside from Indianness in her works, we additionally find chronicled viewpoints. The names of the courageous women like Paro and Parvati have recorded names. She has honestly uncovered the substances of life. She says that every one of her women heroes some place there in the adventure to getting to be themselves. Namita Gokhale has mellowed down in her later books like "The Book of 
Shadows" and "Gods, Graves and Grandmother", contrasted with her presentation novel "Paro: Dreams of Passion".

In 'Paro: Dreams of Passion' she portrays the substances of the life of Delhi and Bombay and how two women are desirous of each other. In the novel, there are two women, Paro and Priya. Paro is dependably herself yet at another level, she is somewhat emotional and she isn't exceptionally keen. So she meets a miserable end. Paro and Priya are two various types of women. Priya was a kind of lady who holds her family together. Paro was a lady who couldn't have cared less and perfect lady is somewhere close to them both. Here one finds the debased state of freedom as women don't get the privilege to appreciate sex uninhibitedly without pestering the moral esteems. Paro isn't utilized to forlorn evenings and changes life accomplice as one move starting with one awkward house then on to the next. She has all the earmarks of being noxious and derisive towards men; and without love. It appears men are by implication in charge of women ' conduct; as B.R. Sewing machine tycoon, to whom Pharaoh had hitched was a man without standards and did not hold the establishment of marriage with deference. Because of such conduct from her significant other, Paro ended up malignant. The character of Priya can be contrasted and Paro. It recommends the life guideline of parallels. The new age needs to push forward rapidly, serenely and with no stuff. Henceforth without obligation, without obligation, one can't procure solidness or joy. It shows that the general public is in motion. Paro is a lady who has illicit relationships with numerous men. Be that as it may, in all actuality, she longs for a man's adoration and security; however ostensibly she seems, by all accounts, to be solid. The depiction of Paro's character is very critical. She speaks to the new lady living in cosmopolitan urban communities of India all alone terms.

The novel "Divine beings, Graves and Grandmother" likewise has a reasonable touch about it. Here she was extremely well drawn out the adroitness, the astuteness of 'Ammi, the way she receives the survival procedure. Grandma is the most grounded character of the novel since she is in each circumstance knows how to alter and influence things to work. There is another intriguing character in the novel, which is Phoolwati. The story revolves around the young lady, Gudiya nom de plume Pooja. She demonstrates her genuine quality after Kalki left her.

Indeed, even the novel features the social conduct and the religious enthusiasm, winning in the general public. The hero moves things further bolstering her good fortune. Kalki charms Gudiya-who has a place with the more youthful age. The author has depicted the contrast between the more established and the more youthful age of the Indian culture. The more established gathering is more useful than the more youthful gathering who show their shortcomings. This is the account of relocation, however, as opposed to being dislodged, they have made their own particular space. Here the minor characters like Phoolwati and Lila are depicted as obedient, intense women who can deal with any circumstance. Lila is obligation cognizant towards Ammi and dedicated; even Phoolwati is completely mindful of her obligation and deals with Gudiya in Ammi`s nonappearance as a genuine mother.

The name of the novel 'A Himalayan Love Story' drives the peruser to deception. The novel manages the topic of hardship in regard of instruction and profession, sexual want and disappointment, suffocation of a confined cold marriage, various issues, the purposelessness of desire, the disgrace and distress of not discovering love after rehashing endeavours, the forlornness and depression that stalks lady and such different things in their works. Through her female characters from various areas of society, Namita Gokhale depicts the lady denied of affection, comprehension, and fraternity which is the focal point of her works.

Thus, the life of Parvati is terrible and lamentable. For the duration of her life, she stays denied of affection since she couldn't get the adoration for her folks and in addition her significant other as her dad passed on ahead of schedule and after some time her mom additionally kicked the bucket because of tuberculosis. She couldn't wed the man she cherished and the man whom she was hitched was a gay who couldn't fulfill her physically and rationally. She gets by through her little girl Irra. Aside from Parvati, the characters of Irra, Marie, Pasang Rampa, and Neera are there. For every one of the women aside from Irra physical viewpoints are of more significance as opposed to inward excellence. Adeleine the Eurasian women is likewise depicted to be emotionless. 
'The Book of Shadows' is Gokhale's self-portraying novel. Like the courageous woman Rachita, she likewise wavers in the shadows throughout her life. In the novel, the characters are looking for affection. Rachita, the hero of the novel, has been distorted by a corrosive assault and this physical mischief is less in contrast with the mental injury she experiences. She withdraws to her youth home to get mental peace and comfort. She wishes to be before, in the immaculate days as her present is aggravating. She sets aside an opportunity to grapple with reality. The author has additionally utilized phantoms to portray her story. Namita Gokhale is a contemporary essayist; subsequently, she has managed the present day issue of corrosive assault from this viewpoint.

In 'The Book of Shadows' and 'Shakuntala: The Play of Memory' one finds the blend of the likelihood and the doubtful components. 'Shakuntala: The Play of Memory' depicts the ideas about the birth-burn are portrayed through the term of Shakuntala, the hero of the novel. Shakuntala is a capable character and the most unusual thing about Shakuntala is that it could be today. The subject of correspondence of women with men has been raised here. It is based on a lady's vision of opportunity. Things haven't changed even today. A large number of years prior things were not far various as they are currently. It demonstrates journey of a lady who needs to think about Hindu sacred texts.

In her non-anecdotal work 'Mountain Echoes: Reminiscences of Kumaoni Women' she depicts the way of life of Kumaon area. The women buckle down in this area since morning till night. Kumaon, the captivating slope locale of western Uttar Pradesh, has been enlivened by four surely understood women of the area. This book depends on the memories of their country. The women whose records are incorporated into the book are celebrated authors Ms. Shivani, Ms. Lakshmi (Jeeya), Ms Tara Pande and Ms. Shakuntala Pande. Every one of these women reflects a social universe that never again exists, that has disintegrated in the standard of modernization and urbanization of the vote based system, instruction and liberation. The book mirrors the most profound and most cosy convolutions, a culture and society in quick progress through the recalled history of four women, every one of them remarkable for their insightfulness and presentation to occasions.
This book additionally hurls fascinating inquiries for contemporary women's activists. We the contemporary women must ask ourselves what we ought to do in our lives to pick up our feeling of selfrule. In the event that we truly need to enable ourselves, at that point we ought to teach ourselves and our little girls to seek after that we carry on with an existence of pride. These women are essential since they appear to have in any event perceived the significance of living these qualities. Be that as it may, the way they deciphered those qualities in their lives relied upon the bigger authentic setting in which they live. They can't give us secure responses to the predicaments that we look at our own particular circumstances, however perusing about their lives gives a thought of how conventional instructed women react to the changing estimations of the circumstances and we in our own particular turn can perceive what course of life would be most reasonable for us.

In her second non-anecdotal work 'The Book Of Shiva' Namita Gokhale has portrayed the ShivaShakti: the compromise of Male-Female polarities. Here she unmistakably discusses an imperative discussion amongst Parvati and Shiva, where Parvati challenges Shiva's sexist state of mind towards her. Parvati was the first of the women's activist women . Namita has a beautiful method for reproducing philosophical discussions between divine beings that moulded the considerations our whole culture rests upon be it the part of Sati, and its distorted comprehension over the ages, or the part of women in the public eye.

Gokhale is exceptionally straight to the point in the depiction of her intense and capable characters... Constantly Gokhale's courageous women paint and repaint their nails now and again; which suggests that they wish to wipe out recollections and seek after a superior tomorrow. From high-class women like Paro, yearning Gudiya, ruling Phoolwati, and blockhead Parvati, all paint their nails or henna their hair. It appears Namita has the fixation for evacuating and painting nails. It is additionally critical that the advanced society, individuals utilize different hues and striking hues to shroud their vacuum. Gokhale additionally needs to toss light on the way that teaches is on the decreasing in the cutting edge, cosmopolitan culture and men and women do lean toward balance and effortlessness yet they favour a bombastic and 
spectacular life. So in that way additionally hues are emblematic of expectation.

"In Search of Sita" (2010) presents papers, discussions and critiques that investigate diverse parts of her life. It returns to folklore, reviving the levelheaded discussion on her introduction to the world, her days estranged abroad, her snatching, the test by flame, the introduction of her children and, at last, her arrival to the earth-offering new elucidations of this baffling figure and her permanent effect on our regular day to day existences. This book isn't just about Sita. It is a dynamic joint effort that brings into centre other solid women characters from Kaikeyi to Surpanakha, from Mandodari to Lakshmana's better half Urmila. Forfeit, abstinence and unquestioning steadfastness are a portion of the standards related to the mainstream view of Sita. Namita Gokhale says,

"Sita endured shamefulness and someplace I feel bad form is wherever in India and it started with this Sita disorder." (2)

"Priya In Incredible Indyaa" (2011) is a book in which author Namita Gokhale brings back some lifechanging characters from her 1984 smash hit 'Paro: Dreams of Passion'. She composes a continuation highlighting Paro's darling companion, Priya. The novel follows her crazy ride life. She is a young lady from India's developing white collar class, who works her way up through social and expert positions to wind up the spouse of an Indian priest, Suresh Kaushal. Priya adapts to social vertigo, disloyalty, menopause and connections and adapts some fundamental lessons watching her new companion Poonam pursue status, sex and fashioner shoes.

Priya has developed into a moderately aged lady, battling with Delhi's high society, her moving toward menopause and finding a reasonable spouse each for her twins. In the meantime, she is likewise battling with every one of the misrepresentations that join being a spouse of an open figure. She continues, recalling her unassuming beginnings in Bombay and where she is present. Namita Gokhale says, "The book is a reflection of our circumstances. On the off chance that Paro... was the primary triumphant chick lit of those days, at that point Priya... must be the primary haglit!"(3)

"The Habit of Love" (2012) is a gathering of thirteen stories that reflect and disguise the lives of women.
There are basically two sorts of stories: contemporary, urban accounts and re-recounting stories from the legends utilizing a female, subaltern perspective. Be that as it may, they all offer the unconventional and idiosyncratic funniness with which they talk about themselves and their lives. The vast majority of these women are not additional customary, but rather straight out of your normal lives however in the meantime, they are broken - either candidly or physically or both. They are cheerful and furious at little things throughout everyday life and enable the perusers to experience their encounters, choices and a large number of articulations in as meagre words as would be prudent. Carefully balanced amongst incongruity and pain, 'The Habit of Love' is rich and intense, curve and melancholic. In these moving stories, she shows both sensitivity and understanding as she discloses the workings of a lady s heart. In the book, "The stories discuss a lady's have to love, instead of the objects of adoration. Women adore enthusiastically, profoundly, frequently indignantly. Genuine love isn't about sexual success, it isn't a triumphant place, however a space of surrender," (4)

Hence Namita Gokhale speaks to a lady's mission for freedom which isn't something new or one of a kind in India. She has the strength to express her women ' basically female sensibility genuinely and earnestly. She has voiced the throbs, issues and fears of weaker sex. The internal mind, the miserable wretchedness, the wounded and broken heart breaks, the despairing, dejection and detachment, the social boycott, the furious disturbance, the battle all have been uproariously articulated. Most works of Namita Gokhale are motivated by the status of women in the public arena and in a man-centric framework. Through her books, she offers the voice to the sufferings, to the distress and agony of women inside their social standards and traditions. Her women are casualties of an ordinary society which does not allow women to stand their ground and considers the very issue of personality emergency as ludicrous pertinent women. Namita Gokhale feels unequivocal about female abuse and male mockery towards the issue of women ' character emergencies. She requests social equity for women, her attention being on an opportunity. Gokhale speaks to new profound quality, as indicated by which lady isn't to be taken as an insignificant toy, a protest of desire and transient delight, yet man's equivalent and respected accomplice. Her women characters without a doubt 
International Journal of Trend in Scientific Research and Development (IJTSRD) ISSN: 2456-6470

uncover her women's activist belief system. Namita Gokhale needs women to perceive themselves.

\section{REFERENCES}

1. Deccan Herald 'Concept of 'Bharatiya Nari' a can of worms' New Delhi, May 29.
2. Personal Interview with Namita Gokhale on April 6, 2014.

3. 'Summer of sequels:' The Telegraph, Sunday, June 12, 2011.

4. Chatterjee Madhusree, Habit of love: The Tribune, Sunday, January 22, 2012. 